\title{
Scenario planning tools for mitigating industrial impacts on First Nations subsistence economies in British Columbia, Canada
}

\author{
David Natcher ${ }^{1}$ - Naomi Owens-Beek ${ }^{2} \cdot$ Ana-Maria Bogdan ${ }^{1} \cdot$ Xiaojing Lu ${ }^{1} \cdot$ Meng Li $^{1} \cdot$ Shawn Ingram ${ }^{1}$. \\ Ryan McKay ${ }^{2} \cdot$ Abigael Rice $^{1}$
}

Received: 23 February 2021 / Accepted: 27 April 2021 / Published online: 7 May 2021

(c) The Author(s) 2021

\begin{abstract}
The Montney Play Trend (MPT) is a $1090 \mathrm{~km}^{2}$ region in northeast British Columbia that produces approximately one-third of western Canada's natural gas output. In response to a proposed expansion of the MPT in 2016, the Government of British Columbia launched a Regional Strategic Environmental Assessment (RSEA) to identify the necessary conditions to achieve sustainable environmental outcomes. In this paper, we describe the methods and scenario planning tools that were developed to estimate how the development of the MPT might affect the subsistence economies of First Nations in the region. To demonstrate the utility of our approach, two impact assessments-Prince Rupert gas transmission pipeline and the Coastal GasLink pipeline-are presented. While no scenario can provide a definitive portrayal of exactly what will happen in the future, the tools that were co-developed are serving as an effective starting point for exploring possibilities that are at least consistent with current knowledge and can serve as a platform for collaborative learning and conflict management.
\end{abstract}

Keywords Impact assessment $\cdot$ Subsistence $\cdot$ First Nations $\cdot$ Collaboration $\cdot$ Scenario planning

\section{Introduction}

In 2016, the Provincial Government of British Columbia launched a Regional Strategic Environmental Assessment (RSEA) for northeast British Columbia, Canada. RSEAs are designed to assess the potential environmental effects, including cumulative impacts, of extractive resource development plans (CCME 2009). Used to enhance the effectiveness of project specific assessments, RSEAs are intended to identify regional priorities and the necessary strategies to achieve more sustainable environmental outcomes (Fidler and Noble 2013). The impetus for the RSEA in

Handled by Kirsten Maclean, Commonwealth Scientific and Industrial Research Organisation, Australia.

David Natcher

david.natcher@usask.ca

1 Department of Agricultural and Resource Economics, University of Saskatchewan, Saskatoon, SK 306-966-4045, Canada

2 Saulteau First Nations, British Columbia, Canada northeast British Columbia was the proposed expansion of the Montney Play Trend (MPT), a $1090 \mathrm{~km}^{2}$ region that produces approximately one-third of western Canada's natural gas output. As of 2020, natural gas producers had invested an estimated $\$ 34$ billion CAD into new drilling and well installations with the expectation that the MPT could ultimately produce more than $50 \%$ of Canada's total natural gas output (Haavardsrud 2016).

Notwithstanding the economic stimulus that the development of the MPT would bring to communities in northeast British Columbia, opposition from environmental groups and First Nations was intense. According to British Columbia's Auditor General, there exists a "profound sense of public alienation from meaningful input into the development of the MPT" and "limited faith exists among First Nations that the provincial and federal governments will adequately manage the cumulative effects of MPT development" (Staples and Askew 2016a, p.1). It was in response to the Auditor General's report that the provincial government launched its RSEA.

In addition to giving residents of northeast British Columbia an opportunity to develop a shared vision for 
regional development (Staples and Askew 2016b, p.20), the RSEA was also used to restore trust between provincial and First Nation governments. As a restorative measure, an RSEA Management Committee was formed with representation from the Treaty 8 Tribal Association, representatives from the energy industry, and senior staff from the provincial government. The mandate of the RSEA Management Committee is to generate trusted information regarding the cumulative impacts of energy development and then use that information to mitigate potentially adverse impacts to First Nations. This includes identifying how the subsistencebased economies (i.e., hunting, fishing and gathering) of First Nations might be adversely affected by the development of the MPT.

In this paper, we describe the methods and tools that were co-developed to estimate how the development of the MPT might affect the subsistence economies of First Nations. While three First Nations participated in this research (Moberly Lake First Nations, McLeod Lake Indian Band, and Saulteau First Nations), in this paper, we present the results from the Saulteau First Nations (SFN) only and were encouraged to do so by SFN leadership who feel an obligation to share their experiences with other Indigenous Nations who are struggling to protect their lands, cultures, and traditional economies from uninformed development.

\section{Background}

The traditional or ancestorial territory of the SFN extends throughout the Peace River basin of British Columbia and Alberta. Within this territory, members of the SFN followed a seasonal round of harvesting activities. In the fall, SFN families would disperse to hunting grounds where moose, elk, caribou, and other large mammals would be harvested. In winter, families would reside on traplines where furbearing animals were procured for food, clothing, and barter. Come spring, SFN families would reunite at fish camps where they would stay through summer, renewing social, economic, and political bonds. The locations and timing of seasonal residencies were adjusted based on the accumulation of environmental knowledge of where resources could be most readily found. This knowledge informed a subsistence pattern that enabled the SFN to thrive in the face of change. In fact, Ridington and Ridington (2013) notes that the most important 'resource' available to the SFN and other Dene-zaa of northeast British Columbia was their intimate knowledge of the land. Wildlife harvesting was merely the outlet that put that knowledge into practice.

With the increasing presence of European settlers, the SFN (officially listed as East Moberly Band No. 169) entered Treaty 8 (1899) with the Dominion of Canada. By entering treaty, SFN leaders were promised a 3,026-hectare (ha) reserve on the northeast end of Moberly Lake (Fig. 1), where SFN members would enjoy exclusive use and protection from future 'white competition' over lands and resources. This reserve area was, however, a very small proportion of their otherwise vast traditional territory that would be made available to European settlement. For this reason, SFN leaders were reluctant to enter treaty in fear that their uses of the land would be constrained and their rights to harvest wildlife would be restricted over time. To appease First Nation concerns, Treaty Commissioners made oral commitments to First Nations that they would be as free after the signing of treaty as they were before, and the treaty would not result in any interference with their usual vocations of hunting, trapping, and fishing throughout their traditional territory (Treaty No. 8 1899).

Despite their assurances, the terms of the treaty did little to thwart the encroachment of European settlement (Harris 2002). In the ensuing decades, the Peace River region became a 'resource frontier' that attracted an onslaught of settlers, traders, and land developers who were drawn to the region's substantial natural resource wealth (Leonard 1995). Further hastening regional development was the $1968 \mathrm{com}$ pletion of the W.A.C. Bennett Dam, located near the town of Hudson's Hope. Heralded as a major engineering feat, the power generated from the Bennett Dam helped transform northeast British Columbia into a "modern industrial society" and enabled the expansion of forestry, agriculture, coal, oil, and gas industries (Loo 2007).

During this period, the SFN and other Indigenous Nations continued to object to the scale and pace at which extractive resource development was occurring and voiced concerns over the cultural and economic impacts it was having in their communities. Those objections led, in 1978, to the Union of British Columbia Indian Chiefs (UBCIC) to commission a study on the social and cultural impacts of energy development in northeast British Columbia, including the potential impacts from the proposed Alaska Highway Gas Pipeline. The assessment focused largely on the tensions between resource extraction and the survival of the 'Indian' economy (Brody 1981). In his final submission to the UBCIC, Brody (1981, p.115) offered two foreboding conclusions: (1) if the rate of industrial development in northeast British Columbia continued, it would not be long before the territory was devoid of wildlife, and (2) unless the territorial rights and interests of Indigenous peoples began to take precedence over the expansion of industrial development, they would soon be deterritorialized and their future cultural existence would be in grave jeopardy. Despite the gravity of his findings, Brody failed to influence decision-makers who have since permitted the development of northeast British Columbia to continue unabated. For the SFN, this has meant an ever-enlarging industrial footprint that now includes more than $128,828 \mathrm{~km}$ of roads, $317,684 \mathrm{~km}$ of seismic lines, 
Fig. 1 Location of the Saulteau First Nations reserve

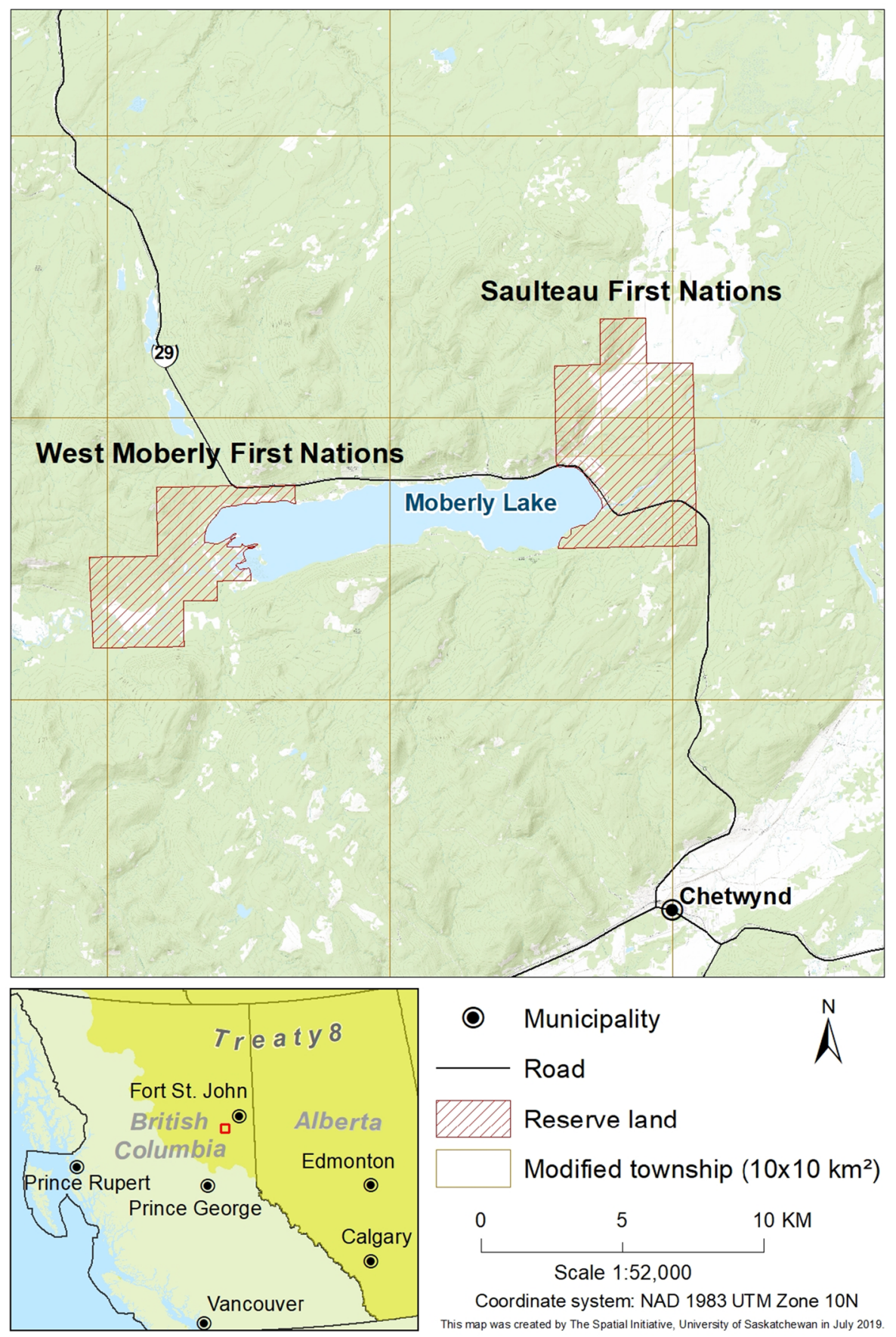

123,536 ha of oil and gas infrastructure, including 6,980 oil and gas wells, and the conversion of 475,320 ha of forest to agricultural land in the SFN territory alone.

This development has occurred despite numerous social and environmental impact assessments being conducted; assessments that Booth and Skelton (2011) argue have been ill-equipped, if not overtly resistant, to the meaningful inclusion of First Nations or their land use concerns. Udofia et al. (2016) attribute this exclusion to the power inequalities that exist between First Nations and the provincial government, whose regulatory decisions typically privilege industrial interests. Although touted by the provincial government as apolitical and based solely on objective scientific evidence (Bond et al. 2020), the impact assessment processes that have been conducted in northeast British Columbia have historically advanced the economic interests of extractive industries, while further entrenching the hegemonic power of government in assessment processes (Dusyk 2011). Westman's (2013) research in Alberta's tar sand regions echo these findings; most notably that most impact assessment 
processes adhere to models of acculturation that remain deeply rooted in post-colonial relations. In the rare cases where First Nations have gained access to decision-making processes, the value of Indigenous environmental knowledge is generally discounted, and the cultural importance of First Nation land use is often dismissed (Udofia et al. 2016, p.168-170). Adding to these challenges, White and Noble (2012, p.63) found that in many cases, consensus is never even reached on what actually constitutes a negative impact. This has, in effect, allowed government and industry to advance project applications despite First Nation objections. For these reasons, First Nations have long objected to the supposed neutrality and efficacy of impact assessments and remain skeptical of their effectiveness to protect First Nation interests.

These concerns weighed heavily in the SFN's decision to participate in the RSEA. Despite their reticence, the SFN recognized that the risks of not participating in the RSEA process outweighed the negative and potentially coopting effects of participation. However, the SFN leadership also recognized that to ensure that their input was not dismissed as anecdotal or merely grievance, new participatory tools were required that not only quantified the potential impacts of development but did so in a visual, testable, and indubitable way. It was with this direction that our research was launched.

\section{Methodology}

Our research involved a mixed methodology that employed both qualitative and quantitative strategies (Fig. 2).

\section{Wildlife harvesting survey}

Wildlife harvesting data were collected through the delivery of a household survey. Due to their commitment to youth engagement, the SFN leadership chose to include students from their summer youth program in the delivery of household surveys. In total, 14 high school students were hired as research assistants who then conducted a survey of all onreserve households $(N=107)$. These students worked under the supervision of the SFN Lands Manager and a SFN Elder.

Prior to the delivery of household surveys, student researchers received 1 week of training. During this time, they: (1) were introduced to the research project, including why it was being done and its expected outcomes; (2) reviewed the survey questions and provided feedback; (3) were instructed on how to record responses and protocols for checking surveys in the field; (4) discussed uncomfortable situations and dealing with problematic respondents; (5) were informed about ethics and performance expectations; and (6) took part in the pretesting of the survey with selected community members. The objective of pretesting was to make sure that questions were correctly phrased (words and phrases made sense for each community context) and that the questions adequately captured the range of possible responses. From its initial development, the household survey went through six iterations before being finalized.

Once finalized, the survey was organized into three sections. Section one collected household demographic information. These data included the number of household members along with their age, gender, and employment patterns. Section two of the survey recorded wildlife harvesting data. The student researchers asked the head(s) of households to recall the number and types of animals harvested by household members during the preceding 12 months. A predetermined list of animal species was used to aid informant recall. In addition to identifying the number and types of animals harvested, respondents were asked to identify on an accompanying map the zones $\left(10 \times 10 \mathrm{~km}^{2}\right)$ where harvesting activities occurred (Fig. 3). Mapping at this scale was done to capture the spatial distribution and concentration of land use and harvesting activities while protecting the confidential nature of specific sites.

Section three of the survey focused on food sharing. Household-heads were asked to identify who in the past year they had given or received food from. Student researchers recorded the types of food shared (e.g., moose, rabbits), the relationships between giving and receiving households (e.g., son to mother, brother to sister), and the corresponding household numbers (coded for confidentiality). The foodsharing component of the survey highlights the harvest and subsequent flow of wild foods between households, and identified households that are either at the core, periphery, or isolated from food-sharing networks. Food sharing data were imported into UCI-Net software and displayed in Netdraw. UCI-Net and Netdraw are commonly used social network analysis tools that are useful for analyzing and displaying associated networks, in this case food-sharing frequency among SFN households.

\section{Data analysis and geodatabase development}

For non-spatial harvesting data, simple descriptive summary statistics were compiled. Household socio-demographic characteristics were manually entered to support the generation of descriptive summary tables and figures. Harvested animal counts were converted to edible food weight (i.e., the amount of consumable meat left after processing) (Ashley 2002). These weights were calculated at species, household, and community levels and mapped according to the harvest locations on the $10 \times 10 \mathrm{~km}^{2}$ map. Plant and berry species were analysed separately as they were associated with harvest location only and not by weight or quantity. 


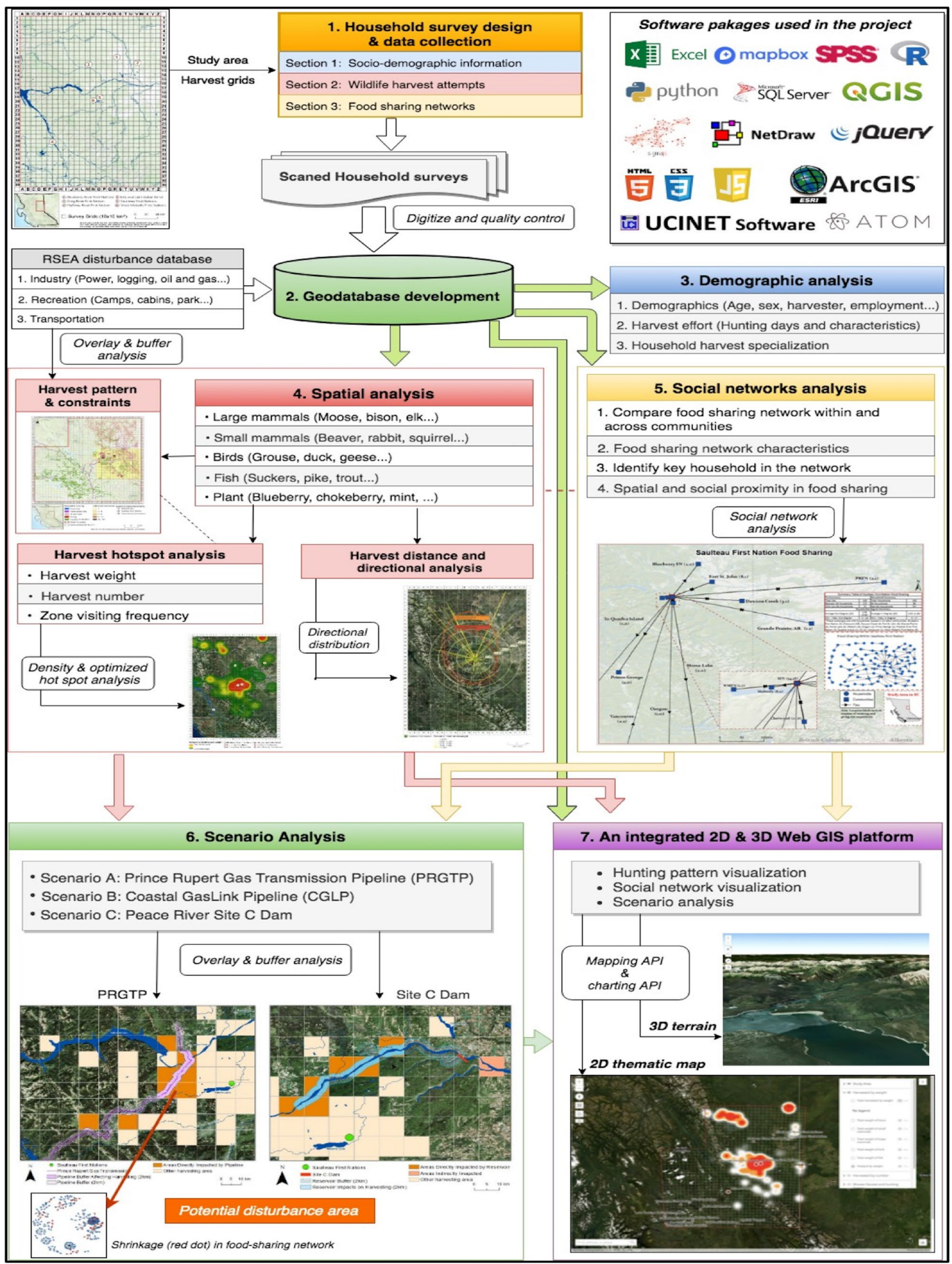

Fig. 2 Mixed methodology research design 


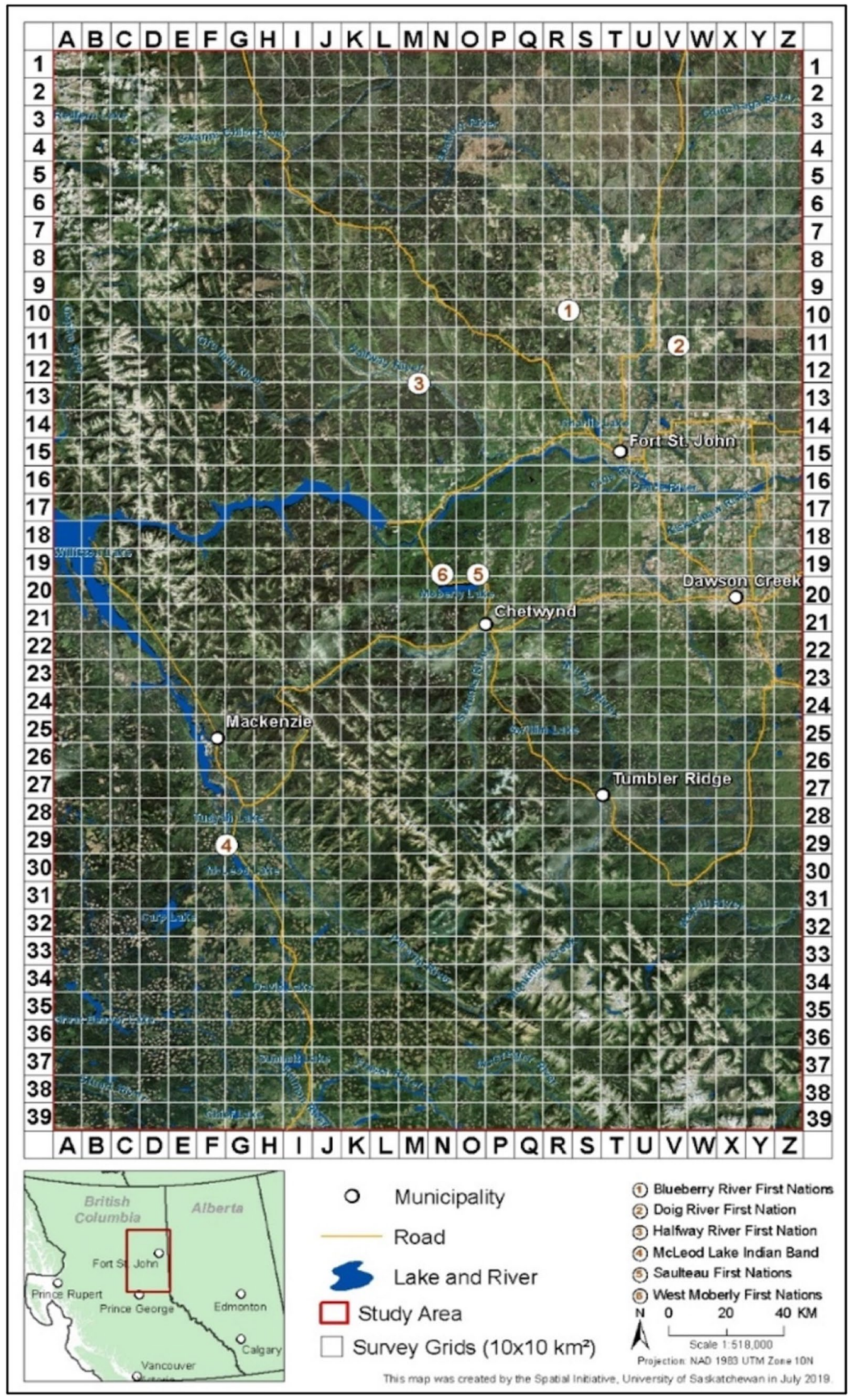

Fig. 3 Map of study area 


\section{Spatial analysis and mapping}

Geographic information systems (GIS) were used to manage the geographic datasets and to investigate the spatial patterns of SFN land use. The main tool used for mapping and spatial analyses was ESRI ArcGIS version 10.6. Thematic maps were generated to show the total harvest by number and types of species harvested, the converted food weight, and the frequency of use by SFN hunters. Hotspot analyses were performed to identify areas of high use and harvesting concentration. Hotspot analyses utilized the geographic location, data frequency, and the weights of discrete zones to derive a data layer covering the entire study area. Hotspot maps were then created by calculating the density of the zones for a certain data theme (e.g., number of moose killed per zone).

Directional maps for animal and plant harvesting were generated by calculating the spatial orientation of the data points to reveal the directional tendencies of SFN harvesting. The Euclidean distance was first calculated between the center of the SFN community to the calculated centroid of the harvest zones, after which we created standard deviational ellipses ( 1 standard deviation) using the directional distribution tool in ArcGIS to summarize central tendencies and directional trends.

\section{Scenario analysis}

Based on the compiled data, a series of scenarios were developed to assess how the development of the MPT and supporting infrastructure might affect subsistence harvesting. The scenario analysis accounts for the SFN's harvesting patterns in relation to existing and proposed industrial disturbances (i.e., well sites, road development, pipelines). To do so, a series of simulations were run based on predetermined industrial setbacks-in this case, the absolute minimum distance that must be maintained between any energy facility (e.g., pipeline or gas plant) and proximal harvesting areas. Within these setbacks areas, certain land use activities are prohibited, such as the discharge of firearms. However, determining appropriate setback distances is not unproblematic. In Canada, no current regulations regarding setbacks currently exist. Prior to 2010, the Sour Pipeline Regulation (SPR) required pipelines to have a setback of $1500 \mathrm{~m}(\mathrm{~m})$ or greater from urban and public facilities. However, later that same year, the SPR was repealed and replaced by the Pipeline and Liquefied Natural Gas Facility Regulation (PLNGFR). The new PLNGFR requires that pipeline projects undergo approval according to the Canadian Standards Association (CSA). However, the CSA's standards can be amended at any time without the approval of the provincial government or the British Columbia Oil and Gas Commission (BCOGC) (McMorran et al. 2013). Moreover, the BCOGC can exempt pipeline companies from any provision of the regulation if it determines that compliance is not practical from the perspective of the company (McMorran et al. 2013). Despite the lack of clear guidelines, the Pipeline Contractors Association of Canada suggests that when wildlife and associated habitats are at risk of endangerment during construction, a setback distance of 2,000 $\mathrm{m}$ (depending on species) should be observed to guarantee species protection. However, there are no requirements that this recommendation is followed.

Due to the variability found in regulatory requirements, we employed four setback distances, ranging from 500, 2000,5000 , and $10,000 \mathrm{~m}$. A setback distance of $500 \mathrm{~m}$, suggested by Xiao (2014), is the most conservative distance. A setback distance of $2000 \mathrm{~m}$ is an alternative distance and has been recommended by the Pipeline Contractors Association of Canada (Hemmera Envirochem Inc 2012). Setback distances of $5000 \mathrm{~m}$ and $10,000 \mathrm{~m}$ were also included due to the spatial resolution defined by the survey's $10 \times 10 \mathrm{~km}^{2}$ grid.

For the purposes of this paper, two pipeline projects are presented to demonstrate the potential impacts to the SFN community's wild food harvest. The first is the Prince Rupert Gas Transmission (PRGT) pipeline. The PRGT project is a proposed natural gas pipeline that would extend $900 \mathrm{~km}$ from Hudson's Hope to Prince Rupert, BC. Although construction has not yet begun, the pipeline has undergone environmental assessment and has been approved by the BCOGC (BCOGC 2018). The second project scenario focused on the Coastal GasLink Pipeline (CGLP). The CGLP is planned to extend $670 \mathrm{~km}$, from Dawson Creek to Kitimat, BC. If constructed, the PRGT and CGLP pipelines will bisect the SFN territory, with PRGT to the west and CGLP in the east of the SFN reserve.

The potential impacts from pipeline development were measured by identifying the number of zones affected at each of the four setback distances. The number of affected zones is positively correlated with the setback distance in terms of the number and types of animals harvested, the food weight acquired, and the frequency of visits by SFN hunters. Original harvest metrics were derived from the survey dataset as three separate layers. Statistics were calculated for the potential loss of harvesting access to affected zones, as was the subsequent impact on food sharing. Combined with the harvesting and mapping components of the survey, food sharing results enabled us to trace the path of wild foods from the point of harvest (i.e., specific zone) through SFN social networks, thereby enabling us to estimate in our scenarios how environmental change (e.g., pipelines) might impact the harvest and availability of wild foods in the SFN community. 


\section{Results}

\section{Wildlife harvesting}

Wildlife harvesting surveys were completed in 96 of the 107 (90\%) SFN on-reserve households. This represents a survey population of 255 SFN members. Among the 96 households that were surveyed, $78(81 \%)$ harvested wildlife and $72(75 \%)$ harvested plants and berries during the previous 12 months. In total, $56,027 \mathrm{~kg}(\mathrm{~kg})$ of wild meat was harvested by SFN households. Large mammals (e.g., moose, bison, deer, elk, bear, and caribou) accounted for $53,370 \mathrm{~kg}$, or $95 \%$ of SFN's food harvest, with moose accounting for $56 \%(31,176 \mathrm{~kg})$ of the total. Other harvested foods include small mammals (e.g., muskrat and squirrel), fish (e.g., pike, lake trout, and whitefish), and birds (e.g., geese, ducks, and grouse). On average, harvesting households spent between 40 and 55 days engaged in harvesting activities, with a smaller number of superharvesting households engaged on a full-time basis. These super-harvesting households $(N=20)$ accounted for $71 \%$ $(39,779 \mathrm{~kg})$ of the total food harvest, with one super-harvesting household procuring in excess of $9,000 \mathrm{~kg}$, or $16 \%$ of the SFN total wild food harvest.

The spatial distribution of harvesting patterns indicates that during the survey year roughly two-thirds of SFN harvesting occurred within a $100 \mathrm{~km}$ radius of the SFN community. However, more distant locations were also used, in some cases, to target specific species (i.e., bison hunting that occurred $220 \mathrm{~km}$ to the northwest) and in other cases to affirm cultural connections with particular places on the land. At a conceptual level, with no constraints or preferences, the harvest zone distribution would be homogeneous. However, in practice the directional orientation of SFN harvesting shows considerable heterogeneity. Within $20 \mathrm{~km}$, there are no directional preferences, with more or less even spatial distribution (Fig. 4). Within $40 \mathrm{~km}$, the directional orientation of SFN harvesting begins to orient towards the west and northwest. This orientation is influenced by existing industrial and agricultural development to the east of the SFN reserve, which has restricted SFN access and regular use.

Given the relatively small number of high harvesting households, food sharing is pervasive within the SFN. Of the 96 surveyed households, 86 households (90\%) shared food with other households in the community. An additional 74 households in 13 other communities also shared food with households from the community, indicating that 160 total households were involved in the community's food-sharing networks. In the 12-month survey period, SFN members shared food 245 times. This is a conservative estimate and does not include shared meals or the

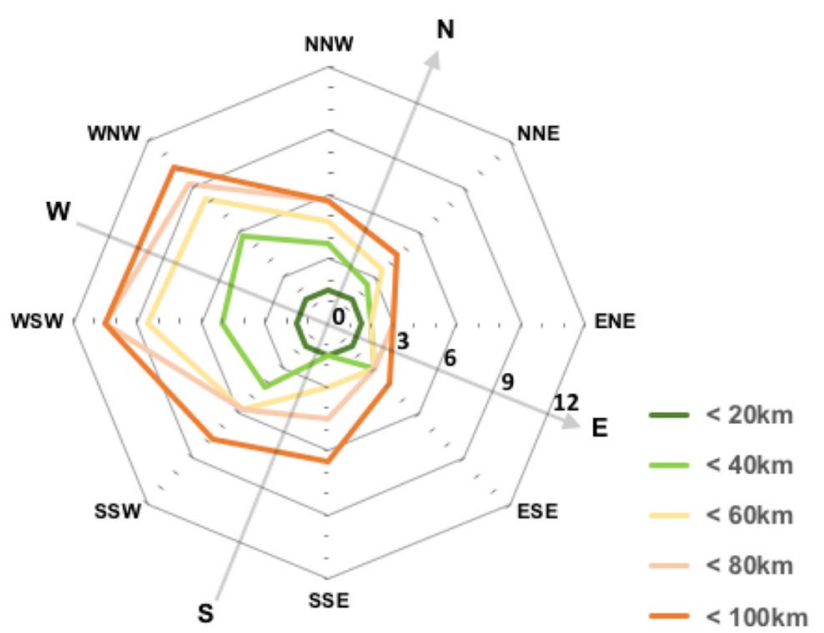

Fig. 4 Directional orientation of Saulteau First Nation land use (2018)

Table 1 Saulteau First Nation (SFN) food-sharing summary

\begin{tabular}{|c|c|c|c|}
\hline \multicolumn{2}{|l|}{ Tie summary } & \multicolumn{2}{|l|}{ Household summary } \\
\hline Total ties & 245 & Total households & 160 \\
\hline $\begin{array}{l}\text { Between SFN house- } \\
\text { holds }\end{array}$ & 171 & SFN households & 86 \\
\hline $\begin{array}{l}\text { With non-SFN house- } \\
\text { holds }\end{array}$ & 74 & Non-SFN households & $74^{\mathrm{a}}$ \\
\hline \multicolumn{4}{|c|}{ Households degree summary } \\
\hline Average out degree & 2.63 & Average in degree & $1.53(2.28)$ \\
\hline Standard deviation & -3.05 & Standard deviation & \\
\hline Min.-max. out degree & $0-18$ & Min.-max. in degree & $0-17$ \\
\hline
\end{tabular}

${ }^{\mathrm{a}}$ These exchanges are with households located in 13 other communities: Blueberry First Nation (2); Chetwynd (28); Dawson Creek (4); Fort St. John (9); Grande Prairie (2); Horse Lake (2); Moberly (8); Oregon (1); Prince George (2); Prophet River First Nation (3); Quadra Island (1); Unknown (3); Vancouver (1); West Moberly First Nation (8)

customary norm of sharing food with guests and visitors. Moose meat was most frequently shared but all other species, including plants and berries, were also exchanged. Food sharing occurred predominately between kin, most often between members of immediate families. For example, $29 \%$ of all exchanges take place between siblings, whereas $16 \%$ of food exchanges occur between non-related friends and hunting partners (Table 1).

\section{Scenario A: Prince Rupert gas transmission (PRGT) pipeline}

The planned route of the PRGT pipeline originates northwest of the SFN reserve and extends south before turning west to the Rocky Mountains and the British Columbia 
coast. The proposed route will affect several zones used by SFN hunters. These zones are shown in Fig. 5, which identifies the effected zones at each of the four setback distances. Based on the four setback distances, the construction of the PRGT pipeline will affect 4 harvest zones within a $500 \mathrm{~m}$ setback, 8 zones at a $2000 \mathrm{~m}$ set back, 15 zones at $5000 \mathrm{~m}$, and 17 zones at a $10,000 \mathrm{~m}$ setback.

At the most conservative setback distance $(500 \mathrm{~m})$, harvesters from 6 SFN households $(8 \%)$ would be negatively affected by the construction of the PRGT pipeline, whereas 19 households (20\%) would be negatively affected by a $10,000 \mathrm{~m}$ setback $(2000 \mathrm{~m}=10$ affected households; $5000 \mathrm{~m}=17$ affected households). At these setback distances, it is estimated that the SFN food harvest would be reduced by $4 \%(2,262 \mathrm{~kg})$ to $24 \%(13,348 \mathrm{~kg})$. For example, at a setback distance of $2,000 \mathrm{~m}$, the total food weight harvested by SFN hunters would be reduced by $9812 \mathrm{~kg}$, or an estimated $18 \%$ of the total SFN food harvest. This includes a $7595 \mathrm{~kg}$ reduction in the SFN moose harvest (Table 2). With moose serving as a primary food source for SFN households, this reduction could potentially jeopardize the food security of some SFN households. Compounding this impact is the
Table 2 Estimated decrease of the Saulteau First Nation wild food harvest, measured in kilograms $(\mathrm{kg})$ of edible food, given setback distances for the Prince Rupert gas transmission (PRGT) pipeline

\begin{tabular}{|c|c|c|c|c|}
\hline & $500 \mathrm{~m}$ & $2000 \mathrm{~m}$ & $5000 \mathrm{~m}$ & $10,000 \mathrm{~m}$ \\
\hline Moose & 1715 & 7595 & 8380 & 9065 \\
\hline Large mammals & 138 & 1770 & 3899 & 3899 \\
\hline Small mammals & 353 & 361 & 361 & 369 \\
\hline Fish & 49 & 64 & 72 & 88 \\
\hline Birds & 7 & 22 & 27 & 28 \\
\hline Total reduction & $\begin{array}{l}2262(4 \% \\
\text { reduc- } \\
\text { tion) }\end{array}$ & $\begin{array}{l}9812(18 \% \\
\quad \text { reduc- } \\
\text { tion })\end{array}$ & $\begin{array}{l}12,739 \\
(23 \% \\
\text { reduction) }\end{array}$ & $\begin{array}{l}13,449 \\
(24 \% \\
\text { reduc- } \\
\text { tion) }\end{array}$ \\
\hline
\end{tabular}

reduction (27-28\%) in small mammal harvest (e.g., rabbits, squirrels), which are often targeted by younger (20-29 years of age) and older ( +65 years of age) households that lack the labor or financial resources to target larger and more geographically dispersed species.

A subsequent effect of the reduced harvest involves diminished frequency of food sharing and a reduction in

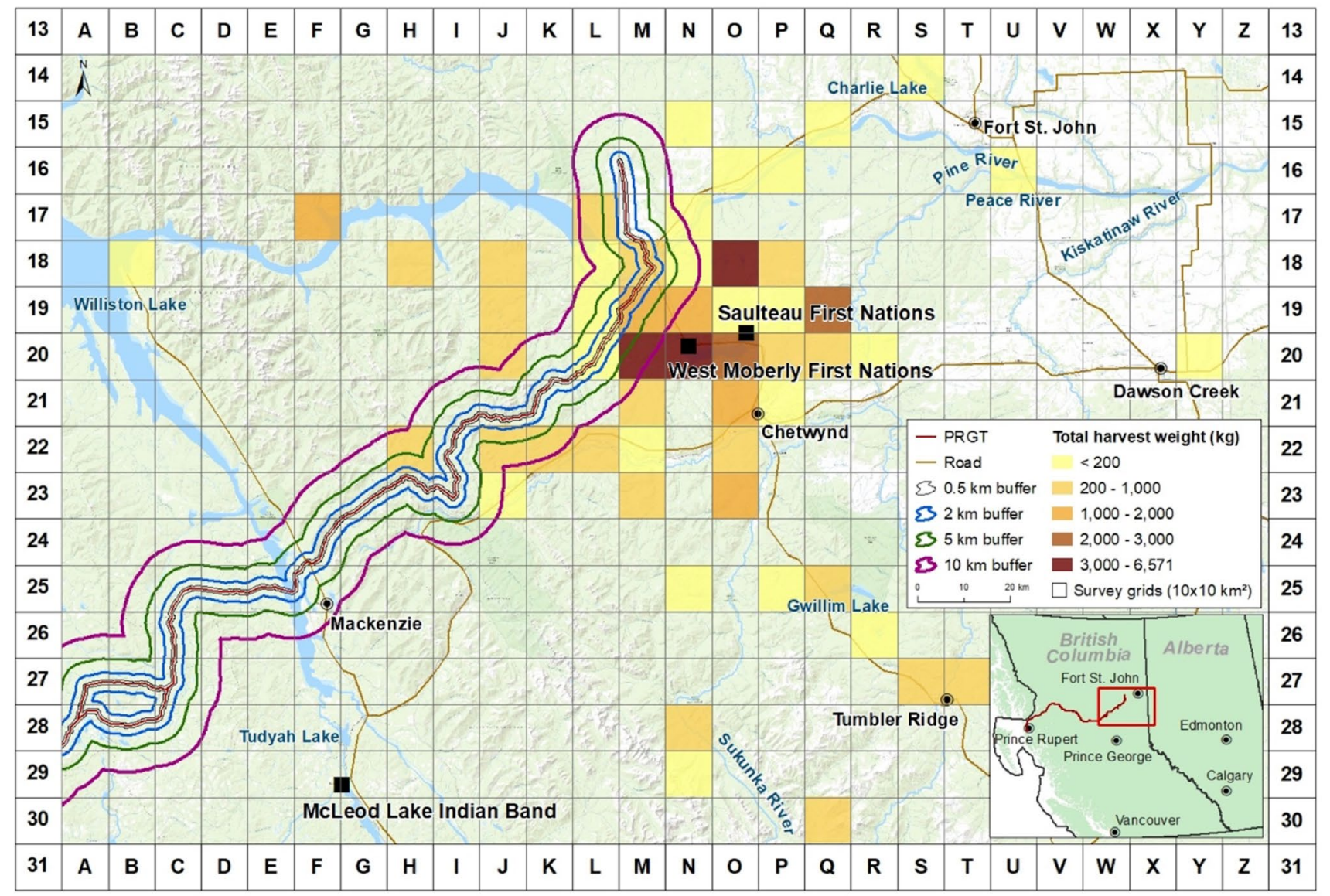

Fig. 5 Prince Rupert gas transmission pipeline and setbacks 
the number of households participating in food exchanges. Figure 6 shows that under each scenario, food sharing could decline by 4-20\%, with 10-35 households being negatively affected. At a $2000 \mathrm{~m}$ setback, the frequency of food exchanges would decline by $16 \%$ ( $N=23$ exchanges), negatively affecting $38 \%$ of SFN households $(N=30)$. Furthermore, 7 households would be excluded entirely from the SFN food-sharing network. At a 10,000 m setback, the impacts are even more pronounced, with a $20 \%$ decline in food-sharing frequency affecting 35 households, 9 of which would be excluded entirely from food sharing.

Those households most affected by the reduction in food sharing tend to be those most vulnerable to economic insecurity. These households are overly represented by younger (20-29 years of age) and older ( +65 years of age) households that harvest little to no wild foods of their own and have limited wage-earning involvement. In these cases, receiving food from other households contributes in a large part to their social, cultural, and economic security.

\section{Scenario B: Coastal GasLink pipeline (CGLP)}

The planned route of the CGLP will originate directly east (Dawson Creek, BC) of the SFN reserve and will extend $670 \mathrm{~km}$ south and then westward to Kitimat, British Columbia. Based on its proposed route, the CGLP will impact 2

\begin{tabular}{l|l|l|l|l|l|}
\hline $500 \mathrm{~m}$ & Number & Percent & $2,000 \mathrm{~m}$ & Number & Percent \\
\hline Households & 10 & 12.7 & Households & 30 & 38.0 \\
\hline Exchanges & 6 & 4.2 & Exchanges & 23 & 16.0 \\
\hline & & & & & \\
\hline
\end{tabular}

Fig. 6 Estimated impact of the Prince Rupert gas transmission pipeline on Saulteau First Nation food sharing 
zones at $500 \mathrm{~m}$ and 2,000 m setbacks, 5 zones at a $5000 \mathrm{~m}$ setback, and 7 zones at a 10,000 m setback. These zones are shown in Fig. 6, which identifies the effected zones at each of the four setback distances (Fig. 7).

At setback distances of $500 \mathrm{~m}$ and $2000 \mathrm{~m}$, hunters from three SFN households would be negatively affected. At $5000 \mathrm{~m}$ and 10,000 $\mathrm{m}$ setbacks, the number of impacted households increases to seven and ten, respectively. Based on the number of zones affected, and the impact on harvesting households, we estimate a $2-3 \%$ reduction in the total food weight harvested by SFN households. For example, with a $2000 \mathrm{~m}$ setback, the SFN wild food harvest could be reduced by $2.2 \%$, or a reduction of $1210 \mathrm{~kg}$ of wild meat. The harvest of moose will be most directly affected, with an estimated reduction of $3.1 \%$ ( $980 \mathrm{~kg}$ ). If, however, a setback distance of $10,000 \mathrm{~m}$ is applied, the reduction in food weight increases to $3.3 \%(1852 \mathrm{~kg})$, with an estimated 5\% (1470 kg) reduction in moose (Table 3 ).

As in the case of the PRGT pipeline, the construction of the CGLP will also affect the frequency and number of households involved in food sharing, although to a lesser magnitude. In this case, we estimate that with setback distances of 500 and $2000 \mathrm{~m}$, two households (2.5\%) would experience a reduction in food sharing (Fig. 8). At setback distances of $5000 \mathrm{~m}$ and $10,000 \mathrm{~m}$, the number of households that are affected doubles $(N=4)$, with a $5 \%$ overall
Table 3 Estimated decrease in the Saulteau First Nation wild food harvest, measured in kilograms $(\mathrm{kg})$ of edible food, given setback distances for the Coastal GasLink pipeline (CGLP)

\begin{tabular}{lllr}
\hline & 500 and $2000 \mathrm{~m}$ & $5000 \mathrm{~m}$ & $10,000 \mathrm{~m}$ \\
\hline Moose & 980.0 & 1470.0 & 1470.0 \\
Large mammals & 209.0 & 209.0 & 349.0 \\
Small mammals & 0.0 & 0.9 & 1.0 \\
Fish & 21 & 21 & 21.0 \\
Birds & 0.3 & 11.0 & 11.0 \\
Total & $1210(2 \%)$ reduction & $1712(3 \%)$ & $1852(3.3 \%)$ \\
& & reduction & reduction \\
\hline
\end{tabular}

reduction in food sharing. While the number of households affected by the CGLP is relatively small compared to the PRGT pipeline, the felt impacts on affected households may be significant since these households are represented by young families (20-29 years of age) that harvest no wild foods of their own and are involved in only part-time seasonal employment. For these families, the impact of the CGLP would likely be significant unless they are able to receive wild foods from others who are currently outside their existing social network. Failing to do so could leave these younger households at greater risk of being food insecure.

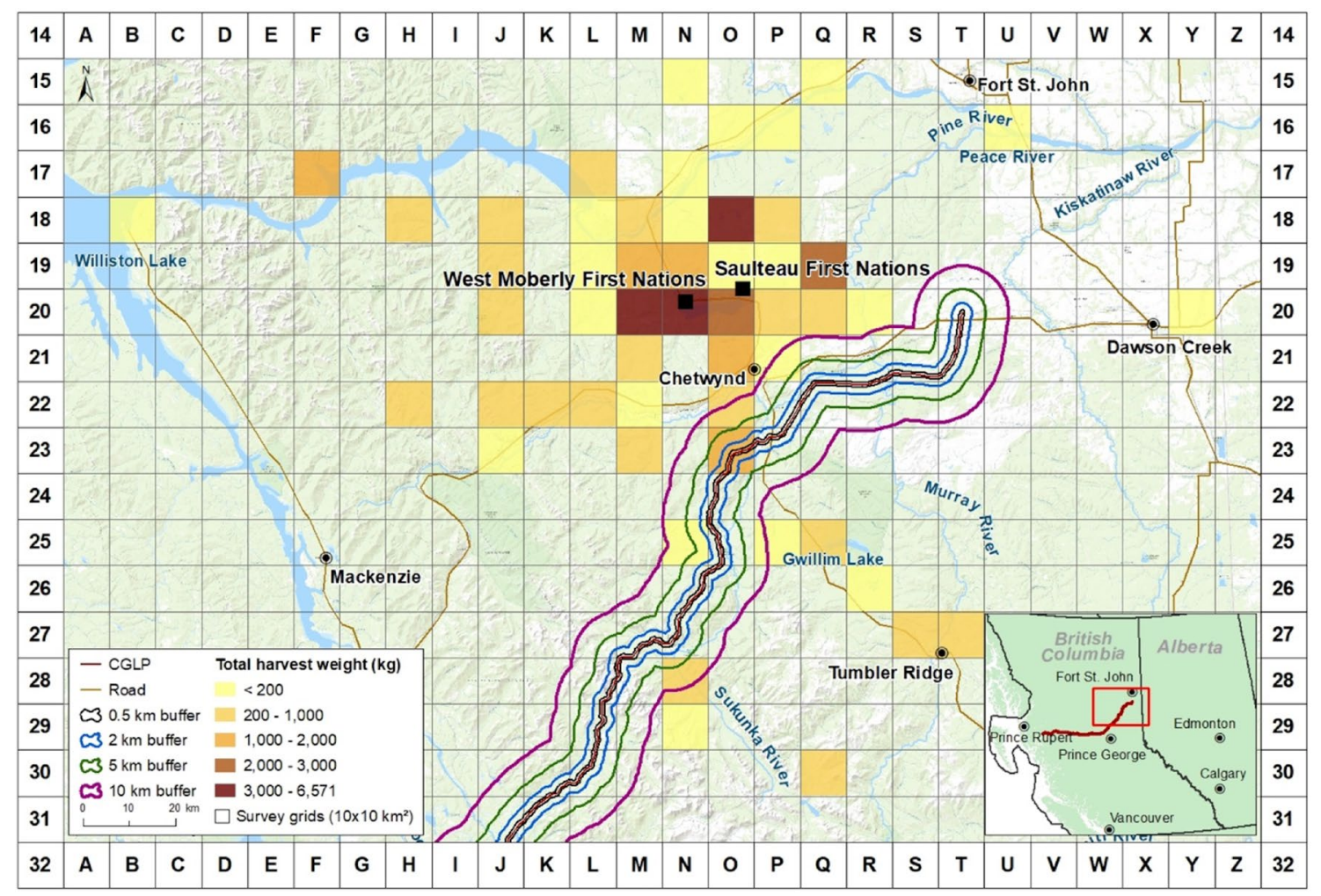

Fig. 7 Coastal GasLink pipeline and setbacks 


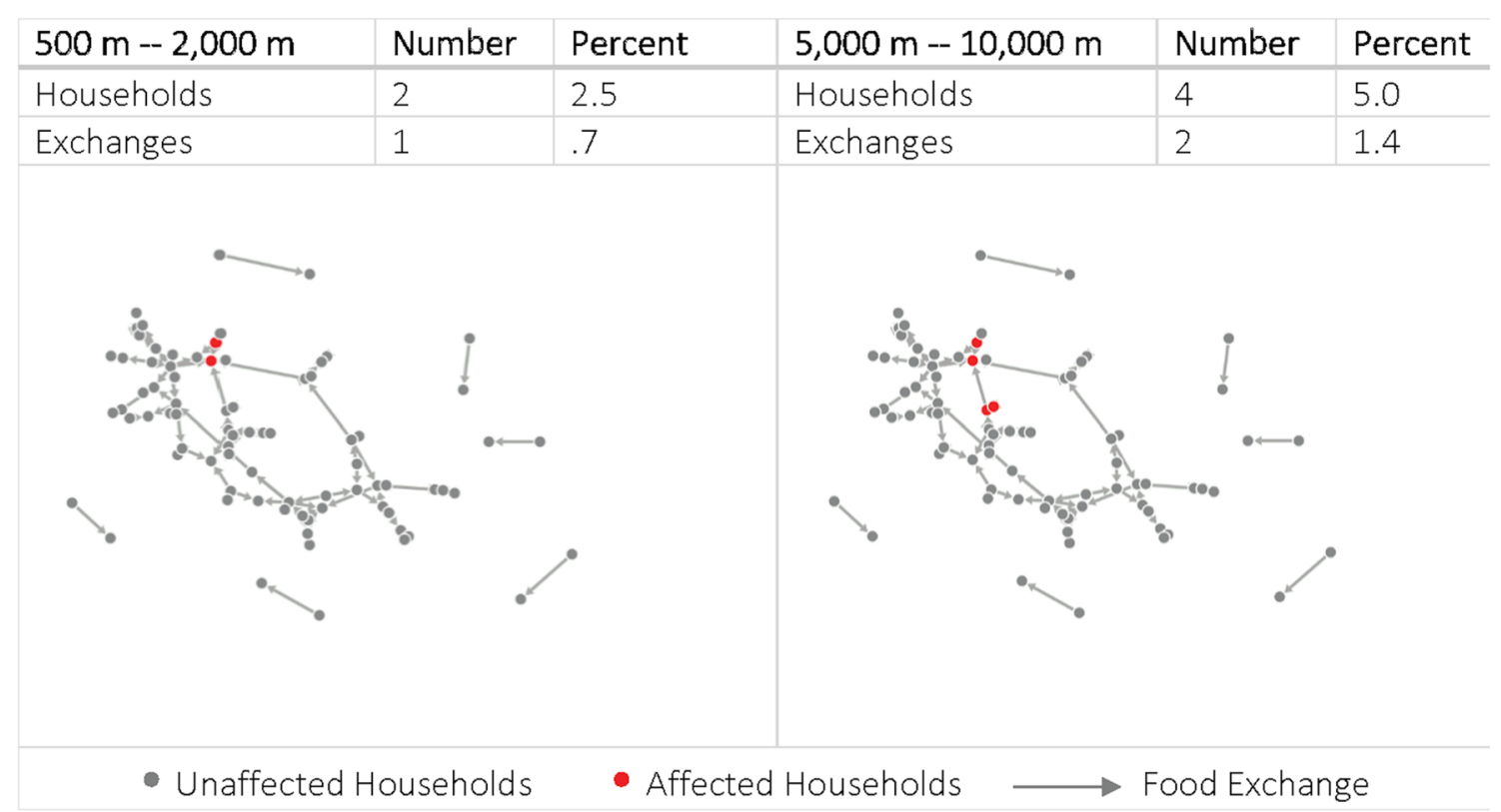

Fig. 8 Estimated impact of the Coastal GasLink pipeline on Saulteau First Nation food sharing

\section{Data management and decision-making}

To facilitate collaboration within the RSEA Management Committee, a 2D and 3D web-based data management platform was developed that is capable of storing, managing, and visualizing spatial data. The $2 \mathrm{D}$ and $3 \mathrm{D}$ tools are integrated within a single web-based platform that is password protected and can be accessed remotely from any Web browser. The 2D visualization platform displays data derived from each of the spatial analyses. At larger scales, the $2 \mathrm{D}$ platform provides an overall view of the study area and allows for spatial queries, such as: (1) what is the proposed route of the PRGT pipeline?; (2) how many hunting zones will be affected after development?; (3) what impact will development have on total food weight harvested?; and (4) how will food sharing between households be affected? Additional information regarding specific zones can also be accessed by clicking on 'zone of interest.' The data viewer contains all the queried information and is a single and accessible option for viewing the raw data (Fig. 9).

The 3D visualization is more interactive and allows for analyses at finer scales. These scales provide an animated view of locations, and to a certain extent brings the 'real world' into desktop and mobile devices. At finer scales, the 3D application allows for a more informed understanding of a potential impact on a specific place or landscape (i.e., harvest location, critical habitat, and cultural sites). Users can scroll through the map creating new perspectives on terrain, existing infrastructure, or critical sites that are valued by SFN members. This 3D application also allows users to visualize harvesting locations in different viewing scales and dimensions. This information can then be used in scenario planning exercises that engage government, industry, and community members in a collaborative learning and planning process.

The use of several different scenarios can further identify the synergies and trade-offs between possible development and mitigation scenarios. Multiple scenarios and data layers can be toggled at the same time, further helping to visualize potentially impacted zones (Fig. 10). While no scenario can provide a definitive portrayal of exactly what will happen in the future, these tools are serving as an effective starting point for exploring possibilities that are at least consistent with current knowledge and can serve as a platform for collaborative learning and conflict management.

\section{Conclusion}

With the signing of Treaty 8 (1899), the SFN was assured that their usual vocations of hunting, trapping, and fishing would not be affected by European settlement, and they would be as free after signing the treaty as they were prior to. Since that time the SFN have been forced to watch much of their traditional territory transformed to meet the economic interests of others. These developments have taken the form of agriculture, forestry, hydroelectric, and the burgeoning energy industry. The proposed expansion of the MPT should, therefore, be seen as the most recent, albeit significant chapter in SFN's long history with extractive industries. 


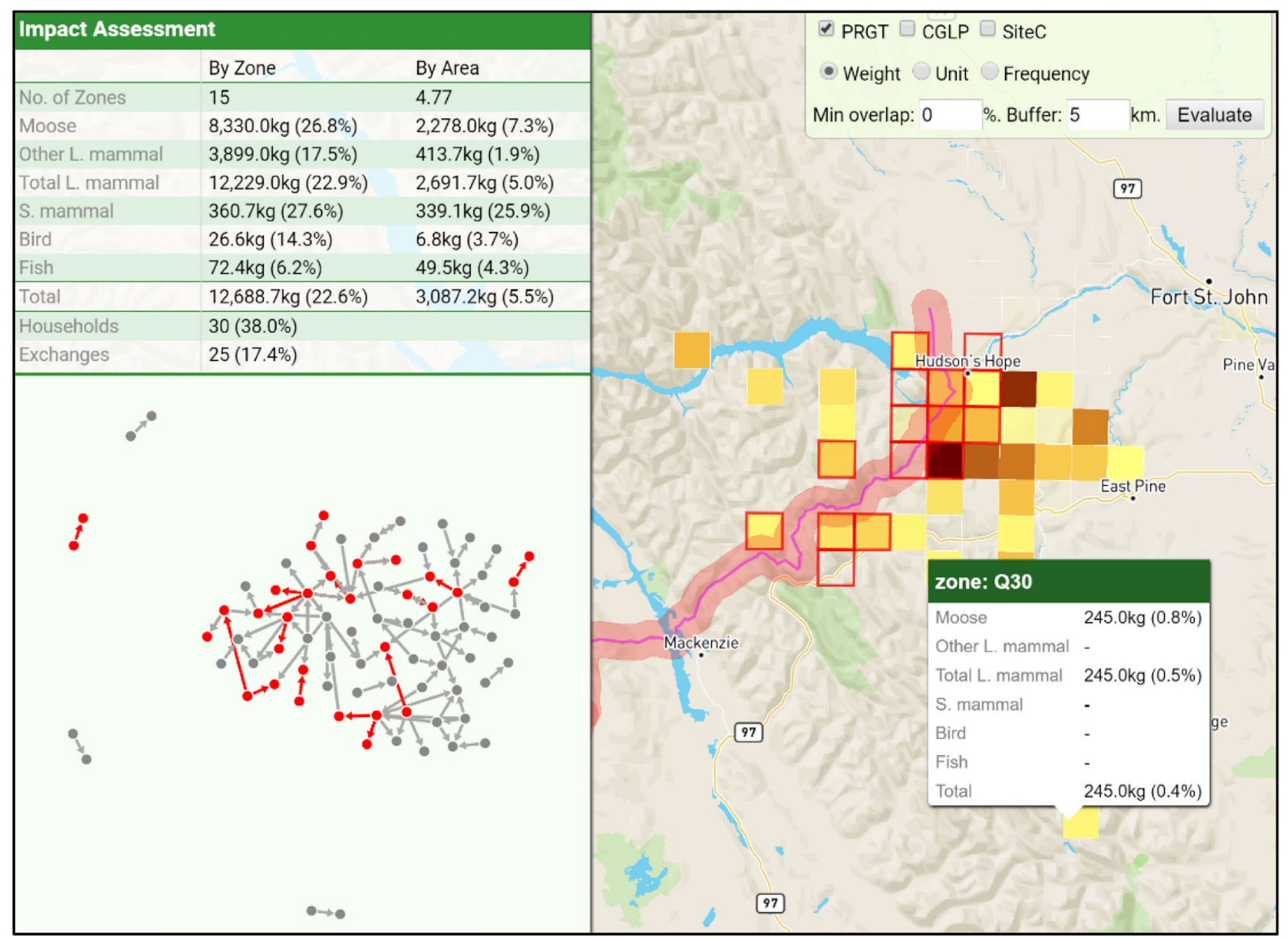

Fig. 9 WEB-based impact assessment tool

When the RSEA was announced in 2016, the SFN was deservedly skeptical. Having borne witness to other assessments, dating back to as early as the 1970s, the SFN was concerned that their participation would again be perfunctory, and the actual impacts experienced by SFN members would be obscured, if not outright dismissed. Their ultimate decision to participate, not unlike the decision made by the Moberly Lake First Nations and the McLeod Lake Indian Band, reflects their unwavering commitment to protect their lands, cultures, and economies.

Under the direction of the SFN leadership, and in coordination with the RSEA Management Committee, we compiled data on the SFN subsistence economy. These data include estimates on harvesting participation rates, the number and types of species harvested, the food weight procured, the directional orientation of land use, and the extent to which food is shared between SFN households. These results were then used to inform a number of impact scenarios that weigh the subsistence needs of SFN members against the economic interests of industry and government.
Our results found that the SFN harvests an estimated $56,027 \mathrm{~kg}$ of wild food annually. These foods are harvested by $81 \%(N=71)$ of SFN households, with a relatively small number $(N=20)$ of households harvesting a large proportion (71\%) of the total food weight. The directional orientation of SFN harvesting is towards the west and northwest and has been influenced by existing industrial infrastructure and an expansive agricultural footprint. The foods that are harvested by SFN hunters are shared through a network of households within the SFN community $(N=86)$ and beyond ( 74 households in 13 communities).

Based on these results, we estimated that the PRGT pipeline could affect between 4 and 17 zones used by $6-19$ SFN households. The loss of access could result in a reduction of between 2262 and 13,348 kg of wild food. In particular, the moose harvest could be reduced by as much as $9065 \mathrm{~kg}$. With the reduced harvest, we estimate food-sharing exchanges could decline by $4-20 \%$, with as many as 35 households (44\%) affected, 9 of which could be excluded entirely from food-sharing networks. Those households that may be at most risk tend to be developing families with 


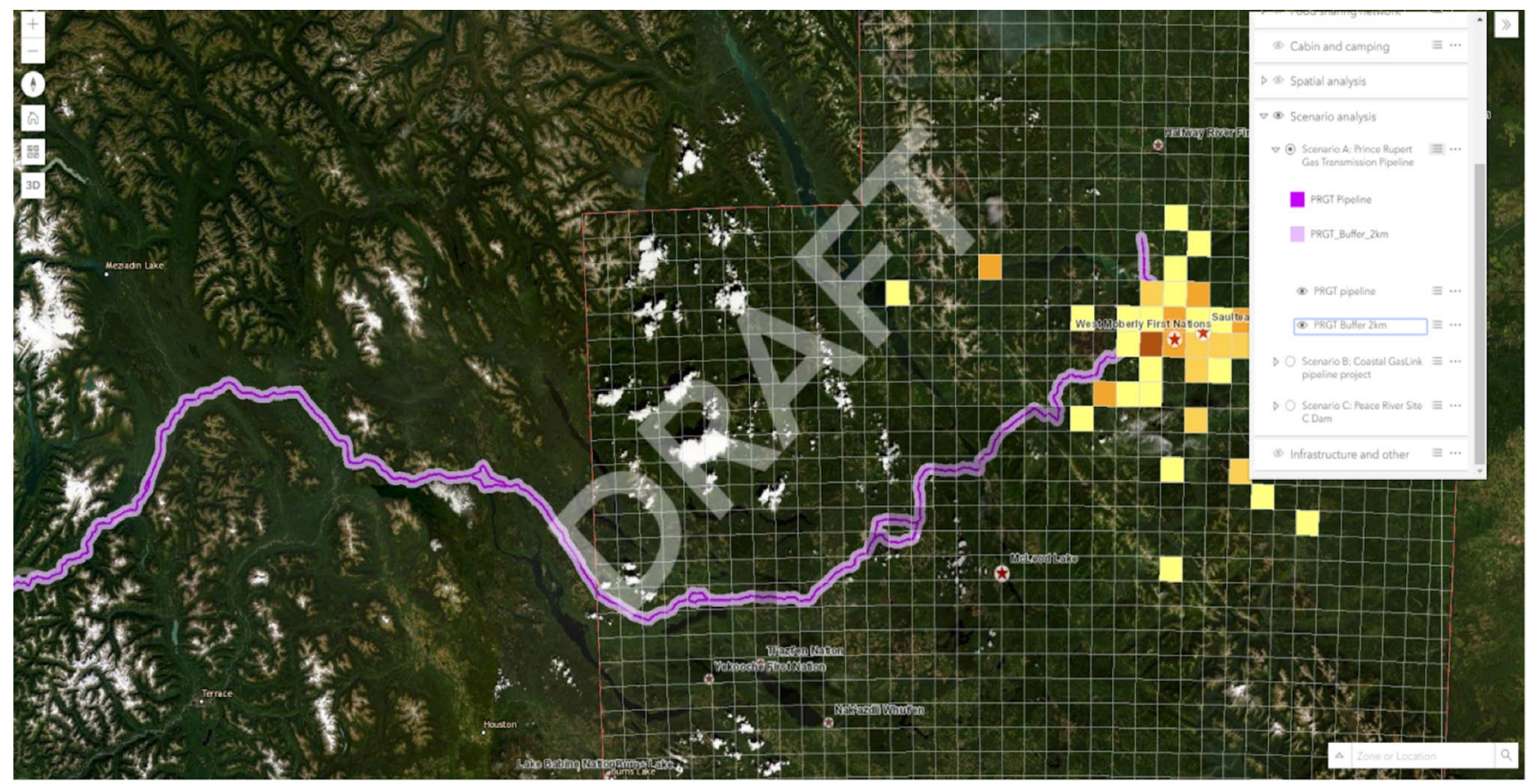

Fig. 10 3D view of Prince Rupert gas transmission pipeline and impacted zones

young children and more senior households who harvest little to no wild food of their own and have limited access to wage-earning employment.

In the case of the CGLP, we estimate that 2-7 zones could be negatively affected and could constrain the harvesting of 3-10 SFN households. This could potentially result in a $3.3 \%$ reduction in the SFN's wild food harvest. With a reduced harvest of approximately $1852 \mathrm{~kg}$, the frequency of food sharing would decline with $5 \%$ of households negatively affected. As in the case of the PRGT pipeline, the households most affected may those that are already economically vulnerable and are at risk of being food insecure. While the potential impacts of the CGLP may be less pronounced than those stemming from the PRGT pipeline, it is important to consider the cumulative and historical impacts of past developments. In this case, the proposed corridor of the CGLP is located in an area of the SFN territory that has been heavily impacted by industrial and agricultural development, which have already constrained SFN land use to a significant degree.

It is important to acknowledge that although these scenarios capture the potential impacts on subsistence harvesting, less observable are cultural impacts that could be experienced. Whereas subsistence includes a range of food procurement activities (harvesting, processing, sharing, consuming), these activities are embedded within a culture system that includes norms, social relationships, worldviews, identities, and environmental knowledge that give subsistence meaning. It is the potential loss of these cultural values that has motivated the SFN to participate in this RSEA and the many other impact assessments that have preceded it.

In the conclusion of Maps and Dreams, Brody (1981, p.276) asserts that, "if the cultural and economic distinctiveness of First Nations are to be respected and guaranteed into the future, then their hunting territories must also be recognized and protected." Forty years after making this decree, the SFN and the provincial government are still discussing how best to reconcile competing interests in the land. For those involved in the RSEA, there is cautious optimism that this process can be used to mitigate the negative impacts First Nations may experience from the development of the MPT and may also serve as a step towards reconciling the political and environmental injustices of the past. We are also hopeful that the lessons learned through this research can inform other impact assessment processes. This may be particularly warranted in light of the U.S. government's decision to cancel the Keystone XL Pipeline that would have extended from Alberta to U.S. refineries in Texas. With the need to access new energy markets, there may be added urgency for the Canadian Government to approve future pipeline submissions, for example the already contested Trans Mountain and Pacific Trials Pipelines. If these projects are advanced, the research presented here may offer useful direction to others, which may help to lessen the conflicts that will undoubtedly arise.

Acknowledgements We gratefully acknowledge the important contributions made by Della Owens, Jim and Laura Webb, Nathan Prince, 
Tamara Dokkie, Alex Grzybowski, Chanda Hunnie, and Robyn Jacobsen.

Author contributions All the authors contributed to the study conception, design, data collection, and analysis. The first draft of the manuscript was written by David Natcher and all the authors commented on previous versions of the manuscript. All the authors read and approved the final manuscript.

Funding This study was funded by the Provincial Government British Columbia, Ministry of Forests, Lands and Natural Resource Operations (Grant \#RSEA01-122016).

\section{Declarations}

Conflict of interest The authors declare that they have no conflict of interest.

Ethical approval This research was reviewed by the University of Saskatchewan's Behavioural Research Ethics Board (Beh-REB) and was found to be in full compliance with the current version of the Tri-Council Policy Statement (TCPS): Ethical Conduct for Research Involving Humans (TCPS 2 2018) (Certificate of Approval BEH \#17253). Ethical requirements for informed consent in research involving Indigenous Peoples are consistent with Article 9.1 of the TCPS for protecting the welfare of Indigenous communities. This research was further guided by individual Research and Information Sharing Agreements signed between the PI and respective First Nations Governments.

Open Access This article is licensed under a Creative Commons Attribution 4.0 International License, which permits use, sharing, adaptation, distribution and reproduction in any medium or format, as long as you give appropriate credit to the original author(s) and the source, provide a link to the Creative Commons licence, and indicate if changes were made. The images or other third party material in this article are included in the article's Creative Commons licence, unless indicated otherwise in a credit line to the material. If material is not included in the article's Creative Commons licence and your intended use is not permitted by statutory regulation or exceeds the permitted use, you will need to obtain permission directly from the copyright holder. To view a copy of this licence, visit http://creativecommons.org/licenses/by/4.0/.

\section{References}

Ashley B (2002) Edible weights of wildlife species used for country food in the Northwest territories and Nunavut. Manuscript Report No 138. Wildlife and Fisheries Division, Government of Northwest Territories, Yellowknife, NWT

BC Oil \& Gas Commission (BCOGC) (2018) Prince Rupert gas transmission. BC Oil \& Gas Commission. https://www.bcogc.ca/node/ 11300/download

Bond A, Pope J, Fundingsland M, Morrison-Saunders A, Retief F, Hauptfleisch M (2020) Explaining the political nature of environmental impact assessment (EIA): a neo-Gramscian perspective. J Clean Prod 244:118694. https://doi.org/10.1016/j.jclepro.2019. 118694

Booth A, Skelton N (2011) Improving First Nations' participation in environmental needs assessment processes: recommendations from the field. Impact Assess Project Apprais 29(1):49-58. https:// doi.org/10.3152/146155111X12913679730395

Brody H (1981) Maps and dreams. Waveland Press INC, Illinois
Canadian Council of Ministers of the Environment (CCME) (2009) Regional strategic environmental assessment in Canada: principles and guidance, Ottawa, $\mathrm{ON}$

Dusyk N (2011) Downstream effects of a hybrid forum: the case of the Site C Hydroelectric Dam in British Columbia, Canada. Ann Assoc Am Geogr 101(4): 873-881. https://www-jstor-org.cyber. usask.ca/stable/27980234

Fidler C, Noble B (2013) advancing regional strategic environmental assessments in Canada's Western Arctic: implementation opportunities and challenges. J Environ Assess Policy Manag 15(1):1-27. www.jstor.org/stable/enviassepolimana.15.1.08

Haavardsrud P (2016) The lowdown on the Montney: Canada's next big energy bet has same high stakes as oilsands. CBC News Online. http://www.cbc.ca/news/business/montney-natural-gas-chall enges-1.3829007

Harris C (2002) Making native space: colonialism, resistance, and reserves in British Columbia. University of British Columbia Press, Vancouver, p 291

Hemmera Envirochem Inc (2012) Site C Clean Energy Project. Canadian Environmental Assessment Agency. https://www.ceaa-acee. gc.ca/050/documents_staticpost/63919/85328/Vol2_Appendix_F. pdf

Leonard D (1995) Delayed frontier: the Peace River Country to 1909. University of Michigan Press, Ann Arbor, pp 256

Loo T (2007) States of nature: conserving Canada's Wildlife in the twentieth century. University of British Columbia Press, Vancouver, $\mathrm{p} 270$

McMorran J, Thielmann T, Sandborn C (2013) Safety buffers between gas wells and pipelines and public schools. The Environmental Law Centre, University of Victoria. http://www.elc.uvic.ca/wordp ress/wp-content/uploads/2015/01/Safety-Buffers-between-GasWells-and-Pipelines-and-Public-Schools_2013Dec12.pdf

Ridington R, Ridington J (2013) Where happiness dwells: a history of the Dane-zaa first nations. University of British Columbia Press, Vancouver

Staples L, Askew H (2016a) regional strategic environmental assessment for Northern British Columbia: backgrounds. West Coast Environ Law. https://www.wcel.org/sites/default/files/publicatio ns/RSEA_NorthernBC_Report_Backgrounder.pdf

Staples L, Askew H (2016b) regional strategic environmental assessment for Northern British Columbia: the case and the opportunity. West Coast Environ Law. https://www.wcel.org/resources/publi cation/regional-strategic-environmental-assessment-northern-briti sh-columbia-case-and

Treaty No 8 (1899) Treaty No. 8 . Typed out version. http://treaty8. bc.ca/wp-content/uploads/2015/07/Treaty-No-8-Easy-Read-Versi on.pdf

Udofia A, Noble B, Poelzer G (2016) Aboriginal participation in Canadian environmental assessment: gap analysis and directions for scholarly research. J Environ Assess Policy Manag. https://www. researchgate.net/publication/307443128_Aboriginal_Participat ion_in_Canadian_Environmental_Assessment_Gap_Analysis_ and_Directions_for_Scholarly_Research

Westman CN (2013) Social impact assessment and the anthropology of the future in Canada's tar sands. Hum Org 72(2):111-120. https:// search-proquest-com.cyber.usask.ca/docview/1429629599?rfr_ id=info $\% 3$ Axri $\% 2$ Fsid $\% 3$ Aprimo

White L, Noble B (2012) Strategic environmental assessment in the electricity sector: an application to electricity supply planning, Saskatchewan, Canada. Impact Assess Proj Apprais 30(4): 284295. https://www-tandfonline-com.cyber.usask.ca/doi/full/https:// doi.org/10.1080/14615517.2012.746836?scroll=top\&need A ccess $=$ true

Xiao J, Wang Y, Shi P, Yang L, Chen L (2014) Potential effects of large linear pipeline construction on soil and vegetation in ecologically fragile regions. Environ Monit Assess 186(11):8037-8048 
Publisher's Note Springer Nature remains neutral with regard to jurisdictional claims in published maps and institutional affiliations. 